\title{
Reducing Hospital Lengths of Stay: A Five-Year Study
}

\author{
Ronald J. Lagoe ${ }^{1 *}$, James H. Abbott' ${ }^{2}$, Shelly A. Littau ${ }^{1}$ \\ ${ }^{1}$ Hospital Executive Council, Syracuse, NY, USA \\ ${ }^{2}$ St. Joseph's Hospital Health Center, Syracuse, NY, USA \\ Email: ^Hospexcl@cnymail.com
}

How to cite this paper: Lagoe, R.J., Abbott, J.H. and Littau, S.A. (2021) Reducing Hospital Lengths of Stay: A Five-Year Study. Case Reports in Clinical Medicine, 10, 160-167. https://doi.org/10.4236/crcm.2021.106020

Received: May 11, 2021

Accepted: June 13, 2021

Published: June 16, 2021

Copyright (C) 2021 by author(s) and Scientific Research Publishing Inc. This work is licensed under the Creative Commons Attribution International License (CC BY 4.0).

http://creativecommons.org/licenses/by/4.0/ (c) (i) Open Access

\begin{abstract}
Hospital length of stay reduction is an important mechanism for improving the outcomes and efficiency of care. This study evaluated the impact of length of stay reduction in the hospitals of Syracuse, New York. Between 2015 and 2020, length of stay reduction saved 7106 inpatient days for adult medicine, and 10,605 patient days for adult surgery in the hospitals. At a conservative late stay rate of $\$ 600$ per day, $\$ 4,263,600$ was eliminated for adult medicine and $\$ 6,363,000$ was eliminated for adult surgery between 2015 and 2020. The study data suggested that the numbers of days saved were the greatest for patients with Major and Extreme severity of illness. At the community level, length of stay reduction can support the efforts of health care providers to free inpatient capacity for patients with Coronavirus and other conditions. It can also generate the efficiency needed to reimburse the costs of care.
\end{abstract}

\section{Keywords}

Hospitals, Hospital Lengths of Stay, Health Care Costs

\section{Introduction}

In recent years, increased attention has focused on the utilization of health care in the United States. This has resulted from the need to accommodate the care of populations in the current system as well as concerns regarding the costs of care [1] [2].

The requirement for health care systems to address population needs has been a focus of efforts to address clinical conditions such as the Coronavirus. The need for hospital bed capacity at the local level has been monitored throughout the nation [3] [4].

It is assumed that inpatient hospitals treat patients within the health care sys- 
tem who have the highest severity of illness. Through medical-surgical and intensive care beds, hospitals provide services for a wide range of medical diagnoses and surgical procedures [5].

Hospitals provide these services through acute episodic care. They treat conditions on an inpatient basis and move patients to post discharge services such as self care, home care, and skilled nursing care [5] [6].

The costs of health care have continued to draw attention in the public and private sectors. Government payers and private insurance companies have struggled to address the costs of care for decades. These costs have increased at a faster rate than other components of the cost of living in the United States and elsewhere [7] [8].

Some efforts to improve hospital inpatient care and related costs have focused on reduction of lengths of stay. These stays and related inpatient costs are generated by nursing and other therapies, tests, pharmaceuticals, and other services. Reduction of hospital stays has usually involved limiting costs for these services [7] [8] [9].

Reducing hospital lengths of stay has also involved the movement of patients to post discharge services at the community level. The process is based on transferring patients to less intense and less expensive care [10].

\section{Population}

This study summarized length of stay reduction in recent years in the hospitals of Syracuse, New York. These hospitals included Crouse Hospital (17,204 inpatient discharges excluding well newborns, 2020), St. Joseph's Hospital Health Center (21,328 discharges, 2020), and Upstate University Hospital (30,988 discharges, 2020).

Historically, the Syracuse hospitals have provided a full range of acute care services to an immediate service area with a population of approximately 600,000 . They have also provided referral center services to the Central New York Health Service Area with a population of approximately 1,400,000 [11].

The Syracuse hospitals have worked cooperatively to improve utilization and outcomes, including length of stay reduction, in their service area. A number of these efforts have been developed through the Hospital Executive Council [11].

\section{Method}

This study focused on efforts by the Syracuse hospitals to reduce inpatient lengths of stay for adult medicine and adult surgery. These are the two largest acute care services maintained by the hospitals, accounting for 71.1 percent of inpatients excluding well newborns during 2020. For purposes of the study, adult medicine and adult surgery were defined as all inpatients excluding pediatrics, obstetrics, neonates, and mental health services.

The study focused on inpatient hospital lengths of stay between 2015 and 2020, the latest complete twelve-month periods available. The research was 
conducted on data for 2015-2020. The years were identified individually so the impact of the coronavirus in 2020 could be separated.

The data were identified for twelve-month periods so that comparisons could be based on similar time periods. For these periods, individual months had the same lengths with the exception of February.

Within these time periods, lengths of stay for the combined hospitals were separated for discharges and lengths of stay by severity of illness. They were identified using the $3 \mathrm{M}^{\mathrm{m}}$ All Patients Refined Diagnosis Related Group System.

In the Syracuse hospitals, reduction of inpatient lengths of stay has been developed though a number of programs. Most of these have focused on patients who have remained in hospitals for extended periods of time.

These initiatives have included case management efforts to monitor and manage patients who require long term care services in the community. They have focused on identifying patients who require home health care, skilled nursing care, and other services and providing them on a timely basis. These programs have included development and distribution of information concerning Difficult to Place patients.

Reduction of lengths of stay in the Syracuse hospitals has also included the Subacute and Complex Care programs. These services have focused on moving patients who require extended care for intravenous therapy, extended wound care, and other services, rather than have them remain in acute hospitals.

The first component of this study identified mean lengths of stay and differences between these stays and severity adjusted national averages for adult medicine and adult surgery for the combined Syracuse hospitals by year between 2015 and 2020. Through this analysis, it was possible to quantify numbers of inpatient days saved during each of these twelve-month periods.

The first and second components of the analysis identified indicators associated with length of stay reduction during the period of the data. They included severity of illness and discharge status of the medical-surgical inpatients in the hospitals. These indicators were evaluated through comparison of 2015 and 2020 inpatient data.

\section{Results}

The initial component of this study focused on medical-surgical lengths of stay for the Syracuse hospitals for 2015-2020. Relevant data are summarized in Table 1.

This information demonstrated that there were substantial reductions in stays for the combined Syracuse hospitals during this time interval. Based on the differences between mean stays and numbers of discharges, the stay for adult medicine declined by 7106 patient days, while the stay for adult surgery declined by 10,605 patient days. The total length of stay reduction for the two services amounted to an average daily census of 48.5 patients.

Within each of the services, the declines in length of stay between 2015 and 2020 generated reductions in patient days by levels of severity of illness between 
Table 1. Inpatient Hospital Mean Lengths of Stay by Severity of Illness, Adult Medicine and Adult Surgery, Syracuse Hospitals, 2015-2020.

\begin{tabular}{|c|c|c|c|c|c|c|}
\hline & \multicolumn{6}{|c|}{ Number of Discharges } \\
\hline & 2015 & 2016 & 2017 & 2018 & 2019 & 2020 \\
\hline \multicolumn{7}{|c|}{ Adult Medicine } \\
\hline Minor & 4236 & 4686 & 5018 & 5243 & 4915 & 3641 \\
\hline Moderate & 11,887 & 13,143 & 13,705 & 14,561 & 13,060 & 10,892 \\
\hline Major & 13,036 & 11,882 & 12,436 & 13,347 & 13,997 & 12,925 \\
\hline Extreme & 4384 & 3318 & 3517 & 4244 & 5665 & 6383 \\
\hline \multirow[t]{2}{*}{ Total } & 33,543 & 33,029 & 34,676 & 37,395 & 37,637 & 33,841 \\
\hline & \multicolumn{6}{|c|}{ Mean Length of Stay (Days) } \\
\hline Minor & 2.66 & 2.60 & 2.52 & 2.55 & 2.55 & 2.56 \\
\hline Moderate & 3.71 & 3.59 & 3.52 & 3.38 & 3.40 & 3.37 \\
\hline Major & 5.70 & 5.86 & 5.76 & 5.63 & 5.15 & 5.09 \\
\hline Extreme & 10.75 & 10.72 & 10.77 & 10.27 & 9.19 & 9.30 \\
\hline \multirow[t]{2}{*}{ Total } & 5.27 & 4.98 & 4.91 & 4.85 & 4.81 & 5.06 \\
\hline & \multicolumn{6}{|c|}{ Patient Days Difference from Severity Adjusted National Average } \\
\hline Minor & -127.08 & -421.74 & -853.06 & -734.02 & -688.10 & -473.33 \\
\hline Moderate & 0.00 & -1577.16 & -2603.95 & -4805.13 & -4048.60 & -3703.28 \\
\hline Major & 130.36 & 2019.94 & 870.52 & -800.82 & -7558.38 & -7755.00 \\
\hline Extreme & 789.12 & 497.70 & 703.40 & -1273.20 & -7817.70 & -8106.41 \\
\hline \multirow[t]{2}{*}{ Total } & 792.40 & 518.74 & -1883.09 & -7613.17 & $-20,112.78$ & $-20,038.02$ \\
\hline & \multicolumn{6}{|c|}{ Number of Discharges } \\
\hline \multicolumn{7}{|c|}{ Adult Surgery } \\
\hline Minor & 6652 & 7784 & 8201 & 7473 & 7184 & 5246 \\
\hline Moderate & 8697 & 8975 & 8678 & 8692 & 8283 & 6667 \\
\hline Major & 4034 & 4106 & 3858 & 3822 & 3878 & 3741 \\
\hline Extreme & 1831 & 1820 & 1834 & 1711 & 2083 & 2321 \\
\hline \multirow[t]{2}{*}{ Total } & 21,214 & 22,685 & 22,571 & 21,698 & 21,428 & 17,975 \\
\hline & \multicolumn{6}{|c|}{ Mean Length of Stay (Days) } \\
\hline Minor & 2.62 & 2.67 & 2.51 & 2.35 & 2.24 & 2.29 \\
\hline Moderate & 3.91 & 4.04 & 3.99 & 3.83 & 3.65 & 3.69 \\
\hline Major & 8.40 & 8.99 & 8.71 & 8.66 & 8.12 & 7.53 \\
\hline Extreme & 24.50 & 21.29 & 19.83 & 18.86 & 17.45 & 15.97 \\
\hline \multirow[t]{2}{*}{ Total } & 6.25 & 5.85 & 5.55 & 5.36 & 5.33 & 5.66 \\
\hline & \multicolumn{6}{|c|}{ Patient Days Difference from Severity Adjusted National Average } \\
\hline Minor & -2394.72 & -2413.04 & -3854.47 & -4707.99 & -5316.16 & -3619.74 \\
\hline Moderate & -3478.80 & -2423.25 & -2776.96 & -4172.16 & -5466.78 & -4133.54 \\
\hline Major & -2311.48 & 82.12 & -1003.08 & -1184.82 & -3296.30 & -5387.04 \\
\hline Extreme & 6701.46 & 819.00 & -1852.34 & -3387.78 & -7061.37 & $-11,303.27$ \\
\hline Total & -1483.54 & -3935.17 & -9486.85 & $-13,452.75$ & $-21,140.61$ & $-24,443.59$ \\
\hline
\end{tabular}

Source: Hospital Executive Council. 
2015 and 2020. The numbers of patient days increased with levels of severity of illness. This suggested that larger amounts of length of stay reduction were associated with higher severity of illness.

In adult medicine, the length of stay decline was produced by all levels of severity. Minor severity patients generated 364.1 patient days. Moderate severity patients produced 3703 patient days. Major severity patients produced 7884 patient days. Extreme severity patients produced 9255 patient days.

In adult surgery, higher severity patients were associated with larger declines in numbers of patient days. Extreme severity patients produced 19,798 patient days. Major severity patients generated 3254 patient days. Moderate severity patients produced 1466 patient days. Minor severity patients generated 1731 patient days.

Reductions in hospital lengths of stay were also associated with differences in adult medicine and adult surgery lengths of stay in the Syracuse hospitals and severity adjusted national averages. These variations were different than those produced by the comparisons of actual discharges and stays in the Syracuse hospitals.

For adult medicine, the reduction in the severity adjusted national average between 2015 and 2020 amounted to 19,245 patient days. The adult surgery length of stay reduction was 25,926 patient days. For the two services combined, the reduction in the average daily census was 123.8 patients.

The second component of the study focused on changes in lengths of stay in the Syracuse hospitals by discharge status. Relevant data are summarized in Table 2.

These data demonstrated that the largest numbers of hospital patients by discharge status in the Syracuse hospitals between 2015 and 2020 were those discharged home with self care and home care. At the same time, the longest stays were generated by patients discharged to nursing homes, as well as deaths and transfers.

For adult medicine, the largest reductions in stays in the Syracuse hospitals between 2015 and 2019 were generated by discharges home. These included a decline in patient days of 4741 for discharges home to self care and a decline of 4244 patient days for discharges to home health care. For adult surgery, the declines in stays by discharge status were produced by discharges to self care, 4,706 and deaths/transfers, 3,158. The longest stays were produced by discharges to nursing homes and deaths/transfers.

These data suggest that the largest reductions in hospital stays in Syracuse have involved discharges home. Additional progress could be more challenging, involving post discharge services such as nursing homes and other providers.

\section{Discussion}

Hospital length of stay reduction is an important mechanism for improving health care utilization. Available information suggests that reducing hospital stays can improve the outcomes and efficiency of care. 
Table 2. Inpatient Hospital Mean Lengths of Stay by Discharge Status, Adult Medicine and Adult Surgery, Syracuse Hospitals, 2015-2020.

\begin{tabular}{|c|c|c|c|c|c|c|}
\hline & \multicolumn{6}{|c|}{ Number of Discharges } \\
\hline & 2015 & 2016 & 2017 & 2018 & 2019 & 2020 \\
\hline \multicolumn{7}{|l|}{ Adult Medicine } \\
\hline Self Care & 18,404 & 17,567 & 18,267 & 19,801 & 19,438 & 16,931 \\
\hline Home Care & 6178 & 6540 & 7325 & 7998 & 7742 & 7447 \\
\hline Nursing Home & 5588 & 5428 & 5509 & 5907 & 6502 & 5267 \\
\hline Deaths/Transfers & 3347 & 3474 & 3564 & 3689 & 3955 & 4196 \\
\hline \multirow[t]{2}{*}{ Total } & 33,517 & 33,009 & 34,665 & 37,395 & 37,637 & 33,841 \\
\hline & \multicolumn{6}{|c|}{ Mean Length of Stay (Days) } \\
\hline Self Care & 3.76 & 3.60 & 3.48 & 3.48 & 3.44 & 3.52 \\
\hline Home Care & 6.27 & 5.81 & 5.61 & 5.67 & 5.41 & 5.70 \\
\hline Nursing Home & 8.19 & 7.79 & 7.94 & 7.61 & 7.45 & 7.91 \\
\hline Deaths/Transfers & 6.82 & 5.96 & 6.16 & 6.04 & 6.05 & 6.57 \\
\hline \multirow[t]{2}{*}{ Total } & 5.27 & 4.98 & 4.91 & 4.85 & 4.81 & 5.06 \\
\hline & \multicolumn{6}{|c|}{ Patient Days Difference from Severity Adjusted National Average } \\
\hline Self Care & $-12,984.9$ & $-11,347.8$ & $-13,762.4$ & $-16,136.3$ & $-20,447.6$ & $-20,175.0$ \\
\hline Home Care & 3488.6 & 2611.6 & 1183.8 & 1108.1 & -3606.0 & -4028.3 \\
\hline Nursing Home & $11,759.1$ & $11,201.6$ & $11,885.0$ & $10,182.8$ & 7610.4 & 7819.2 \\
\hline Deaths/Transfers & -956.2 & -2415.8 & -1644.7 & -3116.3 & -3992.3 & -3800.1 \\
\hline \multirow[t]{2}{*}{ Total } & 712.8 & 605.4 & -1650.4 & -7458.8 & $-19,862.6$ & $-19,918.7$ \\
\hline & \multicolumn{6}{|c|}{ Number of Discharges } \\
\hline \multicolumn{7}{|l|}{ Adult Surgery } \\
\hline Self Care & 11,430 & 12,443 & 12,775 & 13,290 & 13,437 & 10,945 \\
\hline Home Care & 4992 & 5434 & 5152 & 4201 & 3712 & 3485 \\
\hline Nursing Home & 3446 & 3376 & 3212 & 2945 & 3040 & 2286 \\
\hline Deaths/Transfers & 1346 & 1432 & 1432 & 1262 & 1239 & 1258 \\
\hline \multirow[t]{2}{*}{ Total } & 21,214 & 22,685 & 22,571 & 21,698 & 21,428 & 17,974 \\
\hline & \multicolumn{6}{|c|}{ Mean Length of Stay (Days) } \\
\hline Self Care & 3.57 & 3.40 & 3.27 & 3.08 & 2.96 & 3.14 \\
\hline Home Care & 6.87 & 6.53 & 6.20 & 6.56 & 7.02 & 7.47 \\
\hline Nursing Home & 11.16 & 10.88 & 10.42 & 10.62 & 10.86 & 11.73 \\
\hline Deaths/Transfers & 14.12 & 12.66 & 12.52 & 13.06 & 12.37 & 11.61 \\
\hline \multirow[t]{2}{*}{ Total } & 6.25 & 5.85 & 5.55 & 5.36 & 5.33 & 5.66 \\
\hline & \multicolumn{6}{|c|}{ Patient Days Difference from Severity Adjusted National Average } \\
\hline Self Care & $-10,604.0$ & $-12,103.9$ & $-13,033.8$ & $-16,462.8$ & $-20,300.4$ & $-18,871.7$ \\
\hline Home Care & 1127.1 & 380.4 & -2082.2 & -1826.0 & -1806.1 & -3205.2 \\
\hline Nursing Home & 9209.5 & 8704.2 & 7000.1 & 6119.7 & 4674.2 & 3360.6 \\
\hline Deaths/Transfers & 925.2 & -1161.0 & -1272.1 & -406.6 & -2235.6 & -4358.1 \\
\hline Total & -1499.5 & -3954.7 & -9479.8 & $-13,516.0$ & $-21,263.0$ & $-23,149.3$ \\
\hline
\end{tabular}

Source: Hospital Executive Council. 
For health care outcomes, shorter stays can help patients go home sooner, reducing the risk of hospital acquired infections and other adverse outcomes. They can also free up additional inpatient bed capacity for Coronavirus patients and others who may require inpatient admission.

For health care efficiency, shorter stays can reduce patient days and related costs for labor, pharmaceuticals, and tests. This can generate substantial savings for providers and consumers of care.

The study was limited to inpatient discharges and patient days during the five-year period. For these indicators, it focused on inpatient severity of illness and inpatient discharge status.

In this study, length of stay reduction in the combined Syracuse hospitals, saved 7106 - 19,245 inpatient days for adult medicine and 10,605 - 25,926 inpatient days for adult surgery between 2015-2020 depending on the method of calculation. A late stay rate of $\$ 600$ per day would avoid costs such as intensive care and surgery that would not be eliminated. Using this rate, with the conservative numbers of days avoided, $\$ 4,263,600$ was eliminated for adult medicine and \$6,363,000 was eliminated for adult surgery between 2015 and 2020.

The study data suggested that levels of length of stay reduction were the greatest for patients with the highest severity of illness. Between 2015 and 2020, those with Major and Extreme severity of illness saved 17,139 patient days for adult medicine and 23,052 patient days for adult surgery.

This study suggested that hospital length of stay reduction at the community level is an important opportunity for improving health care outcomes and efficiency. Because hospitals provide episodic care, the expeditious movement of inpatients is essential to their ability to provide effective inpatient acute care services.

As populations continue to age, the need for efficient hospital lengths of stay will continue to be important for health care providers and payers. Both of them will have to maintain operational efficiency in an environment of limited resources.

In this study, the experiences of the Syracuse hospitals demonstrated that length of stay reduction can be implemented at the community level. These providers were able to reduce stays for patients with a wide range of severity of illness. It was notable that the largest numbers of patient days reduced were those associated with patients with the highest severity of illness.

These experiences indicate that a wide range of health care professionals, including clinicians, administrators, financial professionals, and long term care staff can have roles in length of stay reduction and share in its benefits. With the pressures that are currently challenging health care at the community level, this is an interesting and exciting opportunity.

\section{Conflicts of Interest}

The authors declare no conflicts of interest regarding the publication of this paper. 


\section{References}

[1] Dentzler, S. (2011) Urgent Measures for an Old Problem. Health Affairs, 30, 1626. https://doi.org/10.1377/hlthaff.2011.0961

[2] Weil, A.R. (2015) Hospital Costs and Quality. Health Affairs, 34, 1263. https://doi.org/10.1377/hlthaff.2015.0786

[3] Goozner, M. (2020) Big Data's Role in Addressing COVID-19. Modern, Healthcare, $50,22$.

[4] Johnson, S. (2021) Will COVID-19 Be the Catalyst for Creating a More Sustainable Health Care System? Modern Healthcare, 51, 12-14.

[5] Hong, C.S., Siegel, A.L., and Ferris, T.G. (2014) Caring for High Need, High Cost Patients: What Makes a Successful Care Management Program? Commonwealth Fund, New York. https://doi.org/10.15868/socialsector.25007

[6] Gawande, A.A. (2011) The Hot Spotters: Can We Lower Costs by Giving the Neediest Patients Better Care? New Yorker, January 24, 2011.

[7] Cushing, W.T. (2004) Extra Hospital Days Can Cost You Plenty. Medical Economics, 81-83.

[8] Riley, G.F. (2007) Long Term Trends in the Concentration of Medicare Spending. Health Affairs, 26, 808-816. https://doi.org/10.1377/hlthaff.26.3.808

[9] Friedman, B., DeLa Mare, J., Andrews, R. and McKenzie, D.H. (2002) Practical Opportunities for Estimating the Costs of Hospital Stays. Journal of Health Care Finance, 291, 1-12.

[10] Oriol, W. (1985) The Complex Cube of Long Term Care. American Health Planning Association, Washington, DC.

[11] Lagoe, R., Pasinski, T., Kronenberg, P., Quinn, T. and Schaengold, P. (2006) Linking Health Services at the Community Level. Canada Health Care Quarterly, 9, 60-65. https://doi.org/10.12927/hcq..18229 